inacy, equivalence of force systems, simple structures, sliding friction, work and energy methods and equilibrium of space systems. Chapter 7 , on work and energy methods, is particularly important as an introduction to energy principles and their power as analytical devices, and should serve to prevent the kind of confusion to which reference is made above. Thus, sections on real and virtual work, potential energy and stability are included in this chapter.

Another important feature of the book is the large number of worked examples which it contains and the appended selection of examples for solution, with answers. It is to be hoped that this book attracts the attention of teachers and students and that, together with similar works in the future, it will lead to more advanced courses in applied statics to supplement those in techniques of structural analysis.

T. M. Charlton

\section{GRASSLAND MANAGEMENT}

\section{Grass Productivity}

By André Voisin. Translated from the French by Catherine T. M. Herriot. Conversion of Tables by M. M. Sandilands. Pp. xiv $+353+41$ photographs. (London: Crosby Lockwood and Son, Ltd., 1959.) 50s. net.

THIS book by André Voisin is timely if only for I the influence it may have in re-stressing the importance of exploiting pasture by better grassland management practices. M. Voisin is a scientist who became a practical farmer; he farms a sixty-acre dairy farm wholly in grass in the Department of Seine Inférieure near Dieppe. He has clearly given much thought to the problems of growing grass and of using it intensively by means of his dairy herd. $\mathrm{He}_{\Theta}$ is an enthusiast particularly in respect of the health of his animals and as a farmer is much concerned with high yields, attaining thereby a satisfactory economic return. He regards the process of grazing as the "meeting of cow and grass" and throughout his book indicates the importance of this concept by laying emphasis on the facts that the yield from grazed pasture enormously depends upon the way animals are put to graze it, and also on when they graze in relation to the physiological growth of the herbage offered them.

High quality and maximum yields from pasture lands in France, as in Britain, come about as a result of good farming practices and one feature of these is the part which animals play in maintaining the botanical balance between species in the pasture. It is by no means certain, however, that the animal is an essential ingredient of the 'high-production pasture complex'. Indeed, many pasture fields in Alpine Europe are highly productive by any modern standard and yet are seldom grazed by animals. The recent interest in so-called 'zero grazing' and the nineteenth century vogue for 'soiling' in Britain involve periodic harvests of herbage and feeding it immediately to animals living away from the field on which it is grown. The success of all these sehemes depends upon maintaining rapid growth and high levels of herbage yields by fertilizer (including dung and urine) applications to the pasture fields. Given these conditions there need be no difficulty in maintaining either immediate yield or balance of botanical constituents upon which continued productivity depends. Success as a viable economic process depends much also upon the input of labour and machinery in relation to net output of animal product, compared with other systems of utilization.

M. Voisin attempts to describe in some detail the mechanism of grazing and perhaps draws too large a distinction between normal grazing by the cow and harvesting by machine. Undoubtedly there are differences between these two mechanisms, but it is dangerous to over-stress the differences out of context. It may be that the mechanies per se of grazing are no more important than is the fact that animals deposit dung and urine on the land from which they graze, and thereby return plant nutrients into circulation and so accelerate the rate of turnover of nutrients within the plant/animal/soil system. M. Voisin makes much of the concept that "cows refuse to work any hours of overtime". The suggestion that grazing animals feed when at pasture for strictly eight hours a day is based on quite fragmentary evidence. In fact there are a number of records in the literature which show that in many circumstances the ruminant will actively graze for many more hours a day than the stipulated 'union rate' of eight hours.

The book is excellently produced and the English translation done well, although a number of errors occur in the text. Some of these are almost certainly due to translation and can be eliminated in a second edition. There is also a good deal of repetition which is possibly more obvious in the English text than in the original. M. Voisin's book, however, should prove a useful addition to the library of any thinking husbandryman. W. Davies

\section{HUMANE EXPERIMENTS}

The Principles of Humane Experimental Technique By Dr. W. M. S. Russell and R. L. Burch. Pp. xiv +238. (London: Methuen and Co., Ltd., 1959.) 30s. net.

LXPERIMENTS on living animals present a C number of difficultios. Individual animals differ from one another in their responses, so it is usual to make numerous replicate observations as a basis for reliable predictions. Animals are sensitive to small changes of many kinds in their environment, and this sensitivity can affect an animal so that it reacts differently to the same experimental stimulus on different occasions. The more disrupting the stimulation, the more violent the reactions of the animal and the more inconsistent its response. These are also the circumstances in which the animal is in all probability distressed or in pain. The various responses which are associated with distress and pain, and which help the animal to overcome or escape from injury greatly complicate any study of the direct response to the initial stimulation, and so are usually undesirable from the scientific as well as the humane aspect. Every step which can be taken to reduce the complexity of an animal's response will reduce also the experimental variation, and so there is good reason for considering humanity and experimental design as one problem.

It is both humane and economical also to use as few animals as possible in experiments. However, it is rather difficult to know to what extent in Britain the use of animals is minimized. The figures available from the Home Office returns are not 